\title{
Melt Rheology of Poly(Lactic Acid)/Low Density Polyethylene Polymer Blends
}

\author{
Kotiba Hamad*, Mosab Kaseem, Fawaz Deri \\ Faculty of Science, Department of Chemistry, Laboratory of Materials Rheology (LMR), \\ University of Damascus, Damascus, Syria \\ E-mail: *kotibahamad@yahoo.com \\ Received June 28, 2011; revised July 26, 2011; accepted September 23, 2011
}

\begin{abstract}
In this work, rheological properties of poly(lactic acid) (PLA), low density polyethylene (LDPE) polymer blends were investigated in the molten state. The experiments were carried on a capillary rheometer. The effect of shear stress, temperature and blending ratio on the flow activation energy at a constant shear stress and melt viscosity of the blends are described. The results showed that the PLA/LDPE polymer blends are pseudo plastic in nature, where there viscosity decreases with increasing shear stress. Also it was found the melt viscosity of the blends decreases with increasing PLA content in the blend.
\end{abstract}

Keywords: PLA, LDPE, Polymer Blends, Melt Viscosity, Flow Activation Energy

\section{Introduction}

Two or more existing polymers may be blended for various reasons. One reason is to achieve a material that has a combination of the properties of the constituents, e.g. a blend of two polymers, one of which is chemically resistant and the other tough. Another reason is to save costs by blending a high-performance polymer with a cheaper material. Blending also benefits the manufacturer by offering: 1) Improved processability, product uniformity, and scrap reduction. 2) Quick formulation changes. 3) Plant flexibility and high productivity. 4) Reduction of the number of grades that need to be manufactured and stored. 5) Inherent recyclability, etc [1].

Poly(lactic acid) (PLA) is well known aliphatic polyesters derived from corn and sugar beets, and degrades into nontoxic compounds in landfill. It can be synthesized from direct condensation of lactic acid or by ring-opening polymerization of cyclic lactide [2], in this way, intermediate lactide (cyclic dimer of lactic acid) is formed in the first step, and after removing condensation product water, the PLA oligomer is depolymerized to lactide, in the second step, purified lactide converted into corresponding high-molecular weight polyesters by catalytic ring-opening polymerization. These new techniques in synthesizing PLA, which allow economical production of high molecular weight PLA polymer, have broadened its uses. PLA was chosen for its high biocompatibility and biodegradability. It has become an alternative to traditional commodity plastics for everyday applications as an environmental friendlily polymer due to its some unique properties such as high strength, high stiffness and resistance to fats and oil. However, brittleness and other properties such as low viscosity, low thermal stability, high moisture sensitivity, medium gas barrier properties, high cost (comparing with PE, PP, PS...) and low solvents resistance (e.g., against water) of the pure polymer are often insufficient for a lot of applications.

Properties of PLA can be modified by polymer blending techniques, where it was blended with several synthetic and biopolymers in efforts to enhance its properties and also to obtain novel materials. PLA have been blended with rubbers [3], thermoplastic starch (TPS) [4-9], poly(butylene succinate) (PBS) [10], poly(butylene succinate adipate) (PBSA) [11], poly(butylene adipateco-terephthalate) (PBAT) [12-15], acrilontryl-butadienestyrene (ABS) [16], polypropylene (PP) [17-19], and polystyrene (PS) [20,21], to obtain materials with lower cost and improved properties.

Polyolefin's industry is still a very dynamic business, where low density polyethylene (LDPE) plays a key role and it has a wide range of applications. LDPE has good properties such as, low cost, processability, resilience and moisture insensitivity. However, the use of LDPE causes serious environmental concerns because it is not 
biodegradable; i.e., it is not biodegraded by the microorganisms present in the environment. Even though recycling has become an alternative, not all post-consumer products may be recycled and, in some cases, this process is not economically sustainable. The waste management problem has prompted the development of, at least, partially degradable plastics, a fact that may be achieved by blending with biodegradable fillers, which can effectively reduce the volume of plastic waste by partial degradation. Therefore, LDPE was blended with native starch or thermoplastic starch (TPS) in efforts to enhance its degradability [22], and it was found that LDPE's degradability can be improved when starch is added to it, although the pure LDPE is not biodegradable. However, the addition of TPS might negatively affect the properties of LDPE. In this case PLA, which has good mechanical properties, can be used as alternative to TPS. Studies on PLA/PE blends were reported by many authors [23-25].

Blends PLA with LDPE offer cost-performance benefits, and enhance the degradability of LDPE. In this work PLA/LDPE blends were prepared using a laboratory scale single screw extruder and characterized in terms of the rheological properties. Such works are very important in the development of composites and blends from biodegradable polyesters. No attention has been given in the past to rheological characterization of PLA/LDPE polymer blends.

\section{Experimental}

\subsection{Materials}

Poly(lactic acid) (PLA) (ESUNTM A-1001) [density = $1.25 \mathrm{~g} / \mathrm{cm}^{3}\left(21.5^{\circ} \mathrm{C}\right), M F I=12.5 \mathrm{~g} / 10 \mathrm{~min}\left(190^{\circ} \mathrm{C} / 2.18\right.$ $\mathrm{Kg})$ ] was supplied by Bright China Industrial Company. Ltd (Shenzhen, China), the selected grade is an extrusion material; it was dried at $70^{\circ} \mathrm{C}$ for $6 \mathrm{~h}$ before using. Low density polyethylene (LDPE) (SABIC ${ }^{\circledR}$ LDPE2308TN00) $\left[\right.$ density $=0.924 \mathrm{~g} / \mathrm{cm}^{3}, M F I=7.5 \mathrm{~g} / 10 \mathrm{~min}\left(190^{\circ} \mathrm{C} / 2.16\right.$ $\mathrm{Kg})]$ was supplied by Sabic (KSA).

\subsection{Blends Compounding}

Blends of PLA/LDPE in different ratios were compounded using a laboratory scale single screw extruder (SSE) $(D=20 \mathrm{~mm}, L / D=25)$ [SHAM EXTRUDER 25D Performance: Kreem Industrial Establishment, Damascus-Syria], it could be operated at different speeds, varied from 0 to100 rpm. The screw has a fluted type mixing device located before the metering zone [26], which can extend the compounding ability of the SSE, in this type of mixers the material is forced to pass at a high shear stress. This brings in some level of dispersing action besides reorienting the interfacial area and increasing the imposed total strain. The flight depth of screw in the metering zone was $1.5 \mathrm{~mm}$, and the helix angle $17.7^{\circ}$. PT124G-124 melt pressure transducer (Shanghai Zhaohui Pressure Apparatus Co., Ltd-China) was located in the die head for measuring the melt pressure.

The screw speed was set at $70 \mathrm{rpm}$ in the blends preparation, and the extruder temperature profile along the barrel was $180^{\circ} \mathrm{C}, 190^{\circ} \mathrm{C}, 200^{\circ} \mathrm{C}, 210^{\circ} \mathrm{C}$ (from feed zone to die). The blends were extruded through a multi holes die $(3 \mathrm{~mm})$, the extrudates were then fed into a granulator, which converted them into granules. The obtained granules were dried at $70^{\circ} \mathrm{C}$ for $6 \mathrm{~h}$ before studying. The compositions of the blends are shown in Table 1.

\subsection{Rheology}

Rheological properties of the blends were studied using a constant pressure circular capillary rheometer. The melt is extruded by the use of dead weights (i.e. constant pressure) rather than constant plunger speed. This instrument, popularly known as the Melt Flow Indexer (MFI), is very popular in the thermoplastics industry due to its ease of operation and low cost, which more than compensates for its lack of sophistication. The parameter measured through the melt flow indexer contains mixed information of the elastic and viscous effects of the polymer. The rheological experiments were carried out at $175^{\circ} \mathrm{C}, 180^{\circ} \mathrm{C}, 185^{\circ} \mathrm{C}$ and $190^{\circ} \mathrm{C}$, and by using $L / R=8$, 15,25 and 36 capillaries. Bagley's correction $[27,28]$ was performed by using the data from the four capillary dies. The apparent shear rate $\left(\gamma_{a}\right)$ is given by:

$$
\gamma_{a}=\frac{4 Q}{\pi R^{3}}
$$

where $R$ is the capillary radius, and $Q$ is the volumetric flow rate. The true shear rate $\left(\gamma_{r}\right)$ is given by:

$$
\gamma_{r}=\left(\frac{3 n+1}{4 n}\right) \cdot \gamma_{a}
$$

where $n$ is the non-Newtonian index depending on temperature, the term $((3 n+1) / 4 n)$ was the Rabinowitsch correction factor. The apparent shear stress $\left(\tau_{a}\right)$ is given by:

$$
\tau_{a}=\frac{R P}{2 L}
$$

Table 1. Compositions of PLA/LDPE blends.

\begin{tabular}{cccccc}
\hline Sample & PLA100 & PLA70 & PLA50 & PLA30 & PLA0 \\
\hline PLA (wt\%) & 100 & 70 & 50 & 30 & 0 \\
LDPE (wt\%) & 0 & 30 & 50 & 70 & 100 \\
\hline
\end{tabular}


where $P$ is the pressure at the capillary entrance, and $L$ is the capillary length. The true shear stress $\left(\tau_{r}\right)$ is given by:

$$
\tau_{r}=\frac{P}{2(L / R+e)}
$$

where $e$ is the Bagley's correction factor. The true viscosity $\left(\eta_{r}\right)$ is given by:

$$
\eta_{r}=\frac{\tau_{r}}{\gamma_{r}}
$$

The values of flow activation energy at a constant shear stress $\left(E_{\tau}\right)$ were determined by using Arrhenius equation form:

$$
\eta_{r}=A \cdot \mathrm{e}^{\frac{E_{\tau}}{R T}}
$$

where $A$ is the consistency related to structure and formulation and $R$ is the gas constant $(8.314 \mathrm{~J} / \mathrm{mol} \cdot \mathrm{K})$.

\section{Results and Discussion}

\subsection{Flow Curves}

The flow curves, ie plots of shear stress versus shear rate for PLA/LDPE blends covering the whole composition range have been measured over a temperature range from $175^{\circ} \mathrm{C}$ to $190^{\circ} \mathrm{C}$ in steps of $5^{\circ} \mathrm{C}$. A typical result for the plot at $175^{\circ} \mathrm{C}$ is shown in Figure 1.

It can be seen that these curves apparently deviate from linear relationship inclining to the axis of shear rate, which means that the homopolymers of PLA, LDPE and their blends are pseudo plastic non-Newton fluids similar to most polymeric melts, and they obey the power law:

$$
\tau=K \cdot \gamma^{n}
$$

where $K$ is the consistency index and $n$ is the non-Newtonian index, which can be calculated from the slope of

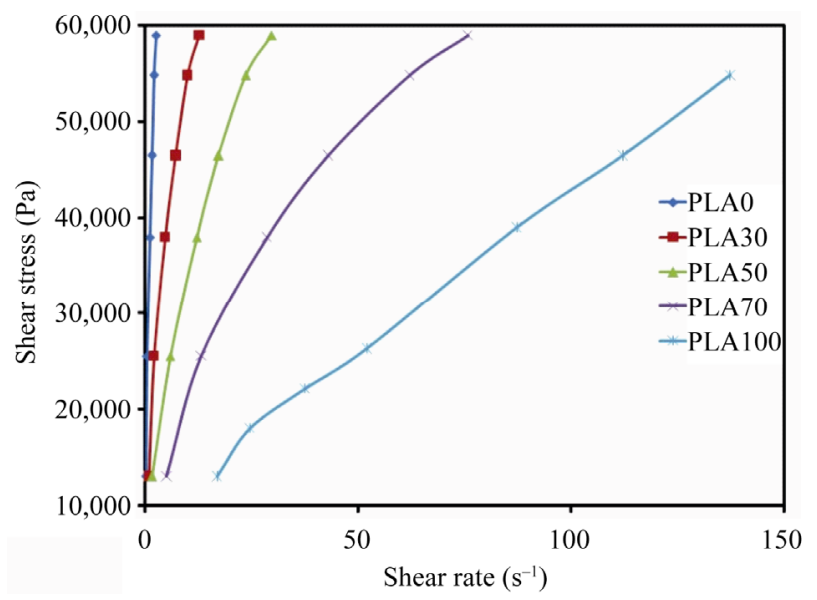

Figure 1. Flow curves of the blends at $175^{\circ} \mathrm{C}$. the lines in Figure 1.

$$
n=\frac{\mathrm{d} \log \tau}{\mathrm{d} \log \gamma}
$$

Figure 2 shows the values of $n$ for PLA/LDPE blend melts over blending ratio at $175^{\circ} \mathrm{C}$. It could be noted from Figure 2, that the values of $n$ were less than 1, implying that PLA/LDPE blend melts were pseudo plastic; similar to most polymer melts. Also it could be noted from Figure 2, that the $n$ values of the blends are less than those of the homopolymers, PLA and LDPE. The value of $n$ describes the deviation from the Newtonian fluids about flow behavior, so it is also called the flow behavior index. A higher value of $n$ reveals less influence of shear rate on flow behavior. In other words, the changes in viscosity upon shear rate are not obvious, so it could be said that the flow behavior of the blend melts is more sensitive to shear rate as compared with the homopolymers.

Also it should be noted from Figure 2, that the PLA/LDPE blends found to be incompatible, where they show a drop in $n$ values and PLA50 is the most nonNewtonian $(n=0.52)$. The compatible polymer blends show high non-Newtonian indexes which are closed to that of their major phase (PLA and LDPE).

\subsection{Melt Viscosity}

Figure 3 shows plots of the melt viscosity versus shear stress for homopolymers PLA, LDPE and the blends at different temperatures. It shows that the viscosity of PLA, LDPE and the blends decreases with increasing shear stress, showing a typical property of pseudo-plastic non-Newton fluids, this behavior was attributed to the alignment or arrangement of chain segments of polymers in the direction of applied shear stress [29].

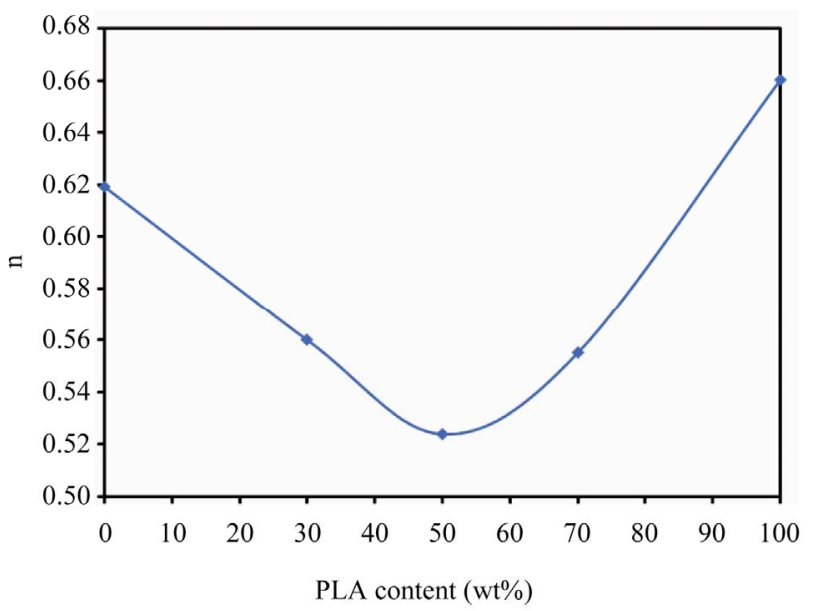

Figure 2. Non-newtonian index of the blends at $175^{\circ} \mathrm{C}$. 
In order to observe how the melt viscosity varies with the blending ratio at different temperatures, cross plots of Figure 3 are given in Figure 4. The high viscosity at a low shear rate provide the integrity of the extrudate during extrusion, and the low viscosity at a high shear rate
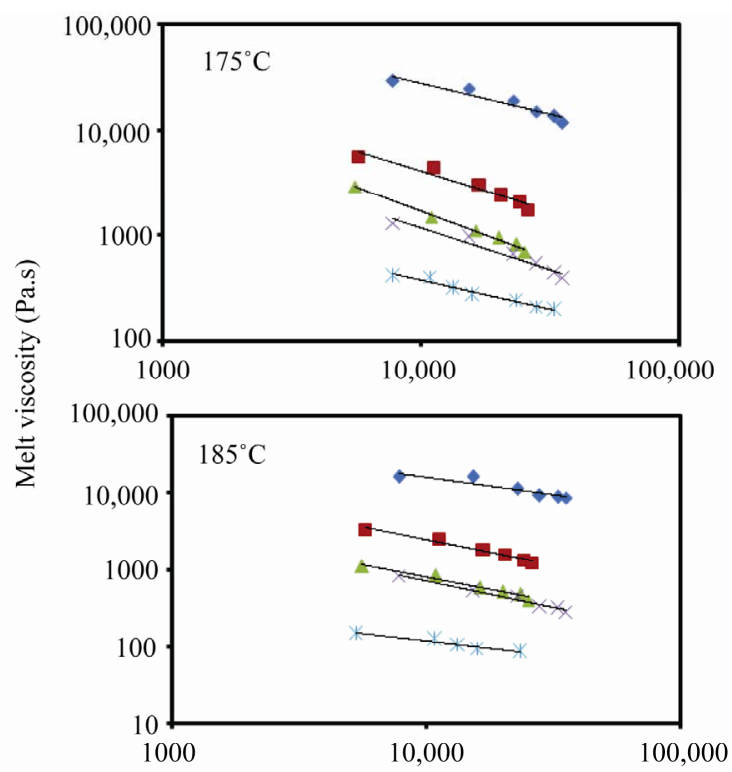

enables low injection pressure, high injection speed and less time of the injection cycle.

It could be noted from Figure 4 that the melt viscosity of the blend decreases with increasing PLA at $175^{\circ} \mathrm{C}$, and this behavior can be attributed to the low melt vis-
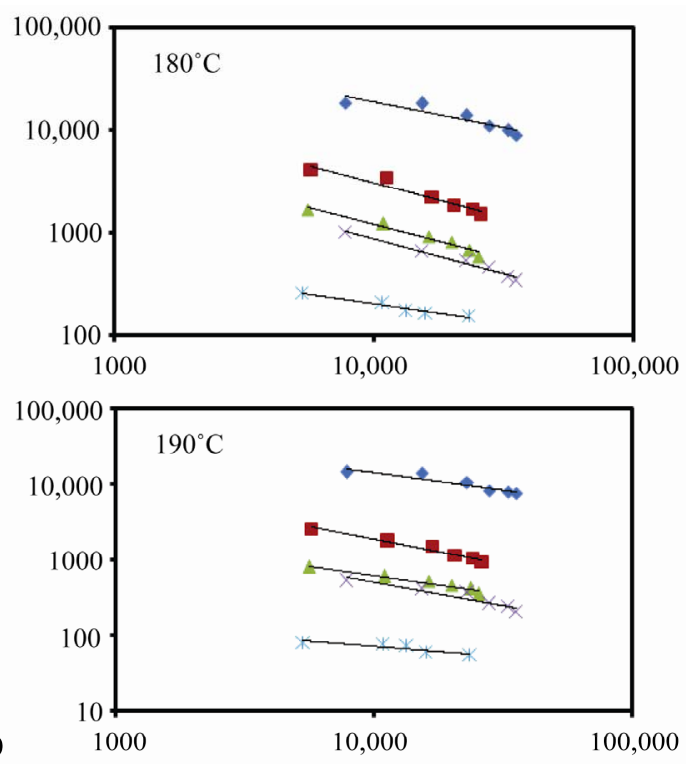

Shear stress $(\mathrm{Pa})$

- PLA0 - PLA30 $\triangle$ PLA50 $\times$ PLA70 $*$ PLA100

Figure 3. Variation of melt viscosity with shear stress for PLA/LDPE blends.
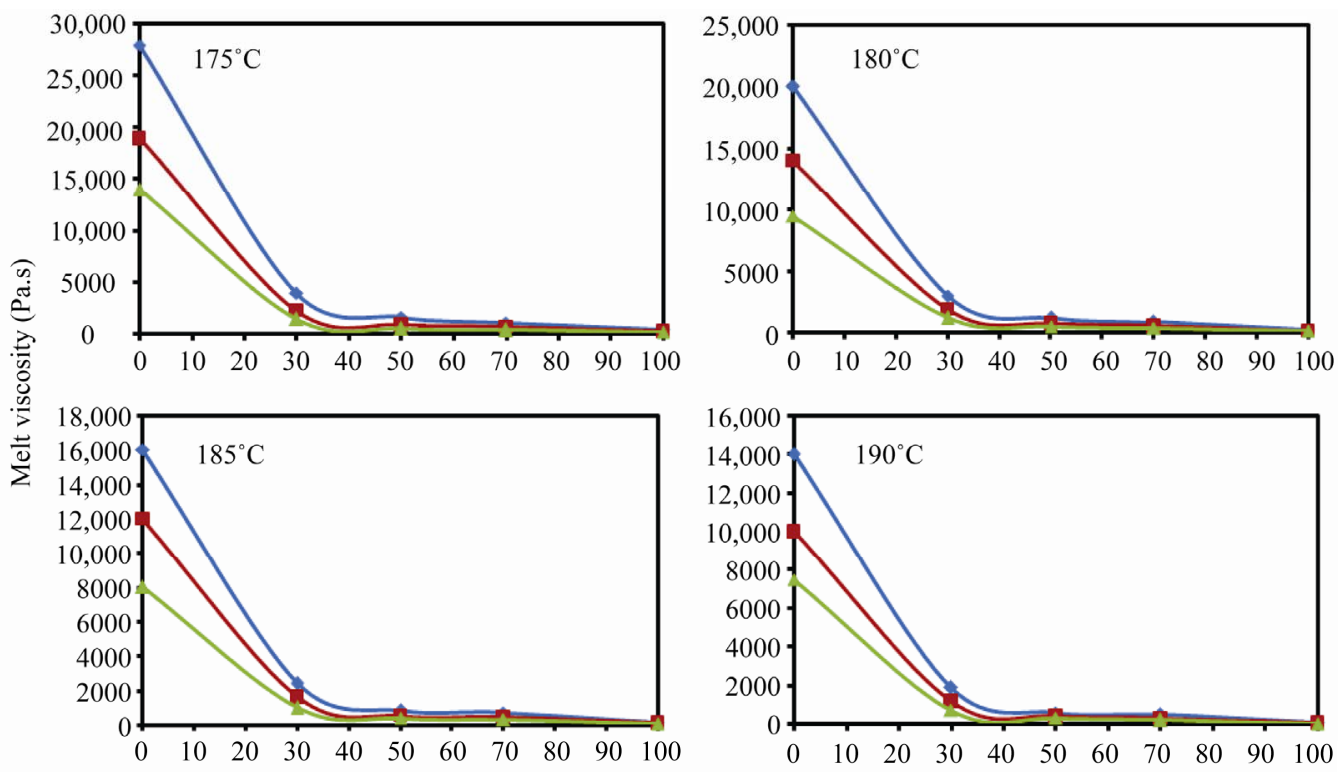

PLA content $(w t \%)$

$\rightarrow 10 \mathrm{KPa} \rightarrow 20 \mathrm{KPa} \nsubseteq 40 \mathrm{KPa}$

Figure 4. Variation of melt viscosity with blending ratio for PLA/LDPE blends. 
cosity of PLA comparing with LDPE. The same behavior can be noted at the different temperatures $(180,185$, $190^{\circ} \mathrm{C}$ ). This behavior can be explained according to the flow activation energy of the blends.

The low melt viscosity of the blends makes them suitable to be used in injection molding process. The good processability (low processing temperature or low pressure) of this blend was detected during injection process of the blends by using NEGRI BOSSI (NB 25) injection machine (Lessona Corporation, Italy). Figure 5 shows samples of the blends and their processing condition (temperature, pressure and cooling time in the mold). It could be noted from Figure 5 that the injection temperature of the blend decreases with increasing PLA content, which was attributed to the decreasing of the melt viscosity with increasing PLA content in the blend.

\subsection{Flow Activation Energy}

The true viscosity variation of the blends with temperature at $\tau=10,20$ and $40 \mathrm{KPa}$ is shown in Figures 6. The true viscosity of PLA, LDPE and all of the blends decreases with increasing temperature. However, the melt viscosity of PLA changes with temperature much more sharply than that of LDPE. The plots of true viscosity versus 1/T shown in Figures 6, give a group of straight lines, which indicates that the relationship between the true viscosity and temperature follows Arrhenius equation (Equation (6)). With a rise of temperature the motion ability of polymer chains enhances, and the resistance between the melt layers decreases relevantly, leading to reduction of the melt viscosity. Flow activation energy at a constant shear stress $\left(E_{\tau}\right)$ could be calculated from the slopes of these lines.

Figure 7 shows the effect of the blending ratio on the flow activation energy, it is clearly seen that the flow activation energy of PLA is greater than that of LDPE, which indicates that the flow behavior of PLA is more sensitive to temperature compared with LDPE. Also, it could be noted from Figure 7, that the flow activation energies of PLA/LDPE blends at $\tau=10^{4} \mathrm{~Pa}$ are between those of PLA and LDPE, whereas at $\tau=4 \times 10^{4} \mathrm{~Pa}$, the flow activation energy of PLA50 is lower than that of LDPE which indicates that the sensitivity of PLA50 viscosity to temperature sharply decreases with increasing shear stress.
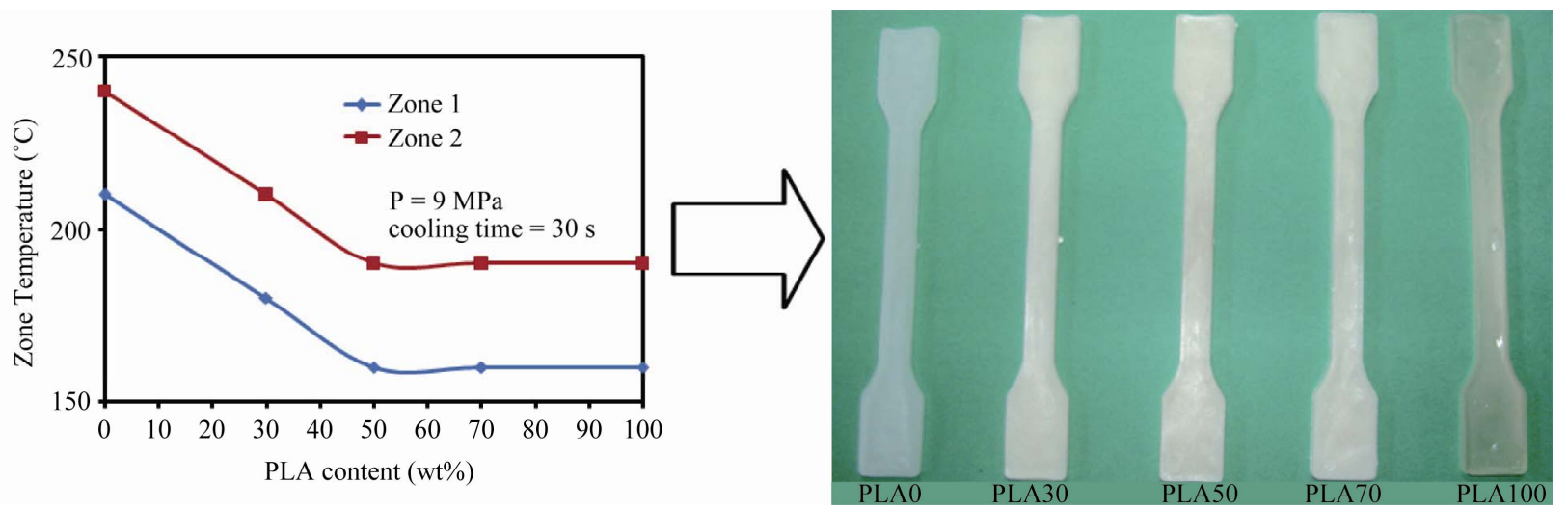

Figure 5. Injected samples and their processing condition.
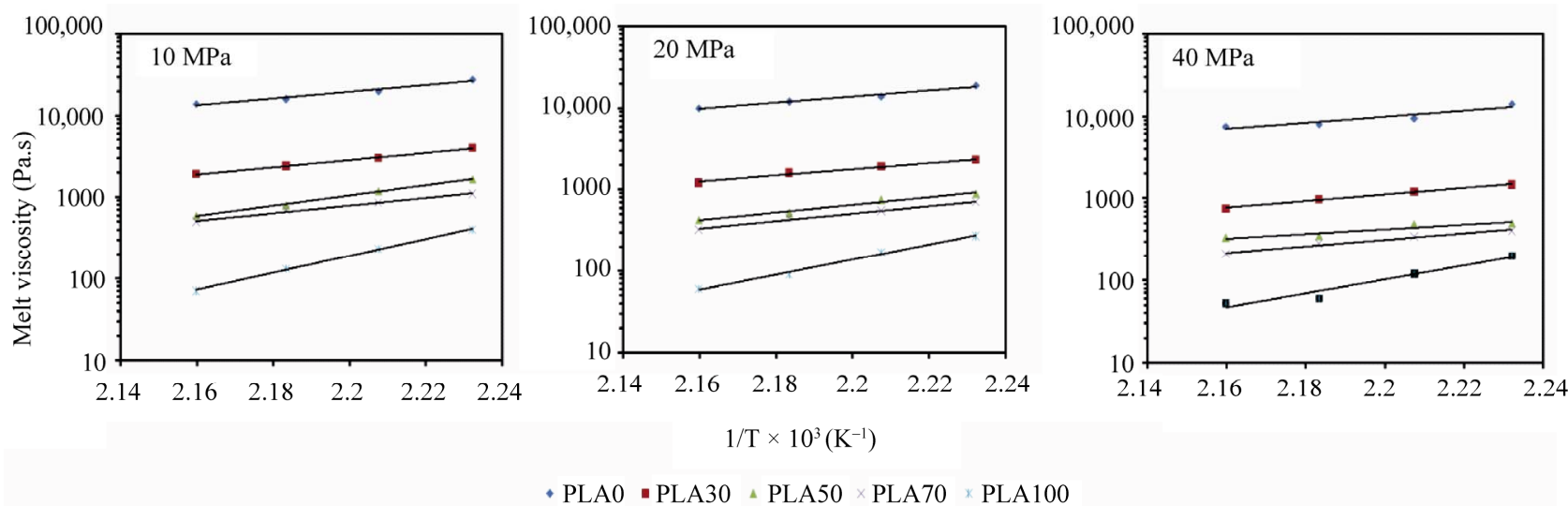

Figure 6. True viscosity versus $1 / \mathrm{T}$ of the sample melts. 


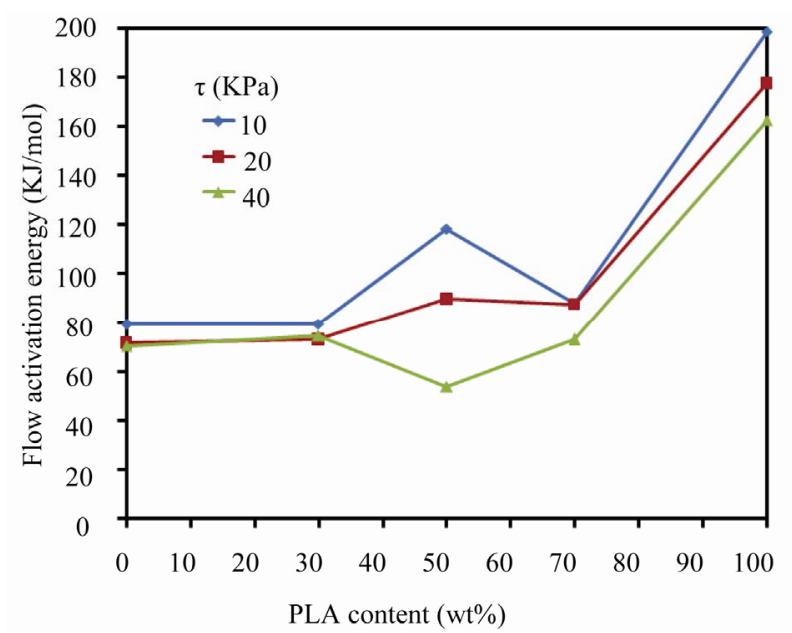

Figure 7. Flow activation energy at a constant shear stress versus PLA content (wt\%).

\section{Conclusions}

In this work, rheological properties of PLA/LDPE polymer blends were studied. The blends were prepared using a single screw extruder. Rheological results showed that PLA/LDPE polymer blends are pseudo plastic in nature; their viscosity decreases with increasing shear rate similar to most polymer melts. The true viscosity of PLA decreases sharply with increasing temperature, whereas the true viscosity of LDPE varies slightly only with temperature. Also it was found that the true viscosity of the blends decreases with increasing PLA content which was attributed to PLA low viscosity. The rheological results indicate that the prepared blends are suitable to be used in injection molding process, where they have low melt viscosity. Such blends are very important in development new biodegradable materials with low cost.

\section{References}

[1] L. A. Utracki, "Polymer Blends Handbook,” Kluwer Academic Publishers, London, 2002.

[2] J. Lunt, "Large-Scale Production, Properties and Commercial Applications of Polylactic Acid Polymers," $\mathrm{Po}_{\mathrm{O}}$ lymer Degradation and Stability, Vol. 59, No. 1-3, 1998, pp. 145-152. doi:10.1016/S0141-3910(97)00148-1

[3] S. Ishida, R. Nagasaki, K. Chino, T. Dong and Y. Inoue, "Toughening of Poly(L-lactide) by Melt Blending with Rubbers,” Journal of Applied Polymer Science, Vol. 113, No. 1, 2009, pp. 558-566. doi:10.1002/app.30134

[4] P. Sarazin, G. Li, W. Orts and B. Favis, "Binary and Ternary Blends of Polylactide, Polycaprolactone and Thermoplastic Starch,” Polymer, Vol. 49, No. 2, 2008, pp. 599-609. doi:10.1016/j.polymer.2007.11.029

[5] N. Wang, J. Yu, P. Chang and X. Ma, "Influence of Formamide and Water on the Properties of Thermoplastic
Starch/Poly(Lactic Acid) Blends," Carbohydrate Polymers, Vol. 71, No. 1, 2008, pp. 109-118. doi:10.1016/j.carbpol.2007.05.025

[6] N. Wang, J. Yu and X. Ma, "Preparation and Characterization of Compatible Thermoplastic Dry Starch/Poly(Lactic Acid),” Polymer Composites, Vol. 29, No. 5, 2008, pp. 551-559. doi:10.1002/pc.20399

[7] N. Wang, J. Yu and X. Ma, "Preparation and Characterization of Thermoplastic Starch/PLA Blends by One-Step Reactive Extrusion,” Polymer International, Vol. 56, No. 11, 2007, pp. 1440-1447. doi:10.1002/pi.2302

[8] N. Wang, J. Yu, P. Chang and X. Ma, "Influence of Citric Acid on the Properties of Glycerol-Plasticized Dry Starch (DTPS) and DTPS/Poly(Lactic Acid) Blends,” Starch, Vol. 59, No. 9, 2007, pp. 409-417. doi:10.1002/star.200700617

[9] M. Huneault and H. Li, "Morphology and Properties of Compatibilized Polylactide/Thermoplastic Starch Blends," Polymer, Vol. 48, No. 1, 2007, pp. 270-280. doi:10.1016/j.polymer.2006.11.023

[10] A. Bhatia, R. Gupta, S. Bhattacharya and H. Choi, “Compatibility of Biodegradable Poly(Lactic Acid) (PLA) and Poly (Butylenes Succinate) (PBS) Blends for Packaging Application,” Korea-Australia Rheology Journal, Vol. 19, No. 3, 2007, pp. 125-131.

[11] S. Lee and J. W. Lee, “Characterization and Processing of Biodegradable Polymer Blends of Poly(Lactic acid) with Poly (Butylene Succinate Adipate),” Korea-Australia Rheology Journal, Vol. 17, No. 2, 2005, pp. 71-77.

[12] J. Ren, H. Fu, T. Ren and W. Yuan, "Preparation, Characterization and Properties of Binary and Ternary Blends with Thermoplastic Starch, Poly(Lactic Acid) and Poly (Butylene Adipate-Co-Terephthalate)," Carbohydrate Polymers, Vol. 77, No. 3, 2009, pp. 576-582. doi:10.1016/j.carbpol.2009.01.024

[13] J. T. Yeh, C. H. Tsou, C. Y. Huang, K. N. Chen, C. S. Wu and W. L. Chai, "Compatible and Crystallization Properties of Poly(Lactic Acid)/Poly(Butylene Adipate-CoTerephthalate) Blends,” Journal of Applied Polymer Science, Vol. 116, No. 2, 2009, pp. 680-687.

[14] M. B. Coltelli, I. D. Maggiore, M. Bertoldo, F. Signori, S. Bronco and F. Ciardelli, "Poly(Lactic Acid) Properties as a Consequence of Poly(Butylene Adipate-Co-Terephthalate) Blending and Acetyl Tributyl Citrate Plasticization," Journal of Applied Polymer Science, Vol. 110, No. 2, 2008, pp. 1250-1262. doi:10.1002/app.28512

[15] H. Xiao, W. Lu and J. T. Yeh, "Crystallization Behavior of Fully Biodegradable Poly(Lactic Acid)/Poly(Butylene Adipate-Co-Terephthalate) Blends," Journal of Applied Polymer Science, Vol. 112, No. 6, 2008, pp. 3754-3763. doi:10.1002/app.29800

[16] Y. Li and H. Shimizu, "Improvement in Toughness of Poly(L-lactic Acid) (PLLA) through Reactive Blending with Acrylonitrile-Butadiene-Styrene Copolymer (ABS): Morphology and Properties,” European Polymer Journal, Vol. 45, 2009, pp.738-746. doi:10.1016/j.eurpolymj.2008.12.010

[17] A. Bourmaud and S. Pimbert, "Investigations on Me- 
chanical Properties of Poly(Propylene) and Poly(Lactic Acid) Reinforced by Miscanthus Fibers," Composites Part A: Applied Science and Manufacturing, Vol. 39, No. 9, 2008, pp. 1444-1454.

doi:10.1016/j.compositesa.2008.05.023

[18] N. Reddy, D. Nama and Y. Yang, "Polylactic Acid/Polypropylene Polyblend Fibers for Better Resistance to Degradation," Polymer Degradation and Stability, Vol. 93, No. 1, 2008, pp. 233-241.

doi:10.1016/j.polymdegradstab.2007.09.005

[19] K. Hamad, M. Kaseem and F. Deri, "Rheological and Mechanical Characterization of Poly(Lactic Acid)/Polypropylene Polymer Blends,” Journal of Polymer Research, Vol. 65, No. 5, 2011, pp. 509-519.

[20] G. Biresaw and C. J. Carriere, "Compatibility and Mechanical Properties of Blends of Polystyrene with Biodegradable Polyesters," Composites Part A: Applied Science and Manufacturing, Vol. 35, No. 3, 2004, pp. 313-320. doi:10.1016/j.compositesa.2003.09.020

[21] K. Hamad, M. Kaseem and F. Deri, "Rheological and Mechanical Properties of Poly(Lactic Acid)/Polystyrene Polymer Blend,” Polymer Bulletin, Vol. 65, No. 5, 2010, pp. 509-519. doi:10.1007/s00289-010-0354-2

[22] H. M. Park, S. R. Lee, S. R. Chowdhury, T. K. Kang, H. K. Kim, S. H. Park and C. S. Ha, "Tensile Properties, Morphology, and Biodegradability of Blends of Starch with Various Thermoplastics," Journal of Applied Polymer Science, Vol. 86, No. 11, 2002, pp. 2907-2915. doi:10.1002/app.11332
[23] Y. F. Kim, C. N. Choi, Y. D. Kim, K. Y. Lee and M. S. Lee, "Compatibilization of Immiscible Poly(L-lactide) and Low Density Polyethylene Blends," Fibers and Polymers, Vol. 5, No. 4, 2004, pp. 270-274. doi:10.1007/BF02875524

[24] H. Balakrishnan, A. Hassan and M. U. Wahit, "Mechanical, Thermal, and Morphological Properties of Polylactic Acid/Linear Low Density Polyethylene Blends,” Journal of Elastomers and Plastics, Vol. 42, No. 3, 2010, pp. 223239. doi:10.1177/0095244310362403

[25] G. Singh, H. Bhunia, A. Rajor, R. N. Jana and V. Choudhary, "Mechanical Properties and Morphology of Polylactide, Linear Low-Density Polyethylene, and Their Blends,” Journal of Applied Polymer Science, Vol. 118, No. 1, 2010, pp. 496-502.

[26] Z. Tadmor and C. G. Gogos, "Principles of Polymer Processing,” John Wiley \& Sons, Inc., Hoboken, 2006.

[27] C. D. Han, "Rheology and Processing of Polymeric Materials (Polymer Processing),” Oxford University Press, New York, 2007.

[28] E. B. Bagley, "End Corrections in the Capillary Flow of Polyethylene,” Journal of Applied Physics, Vol. 28, No. 5, 1957, pp. 624-627. doi:10.1063/1.1722814

[29] W. Sinthavathavorn, M. Nithitanakul, B. Grady and R. Mangaraphan, "Melt Rheology and Die Swell of PA6/ LDPE Blends by Using Lithium Ionomer as a Compatibilizer,” Polymer Bulletin, Vol. 63, No. 1, 2009, pp. 23-35. doi:10.1007/s00289-009-0063-X 